\title{
Discussion of "Clogging of pervious concrete pile caused by soil piping: an approximate experimental study"
}

\begin{tabular}{|r|l|}
\hline Journal: & Canadian Geotechnical Journal \\
\hline Manuscript ID & cgj-2018-0339 \\
\hline Manuscript Type: & Discussion \\
\hline Author: & 11 -Jul-2018 \\
\hline $\begin{array}{r}\text { Complete List of Authors: } \\
\text { Keyword: }\end{array}$ & $\begin{array}{l}\text { Dallo, Yousif; Yancheng Institute of Technology, } \\
\text { Xu, Gui-Zhong; Yancheng Institute of Technology, Geotechnical } \\
\text { Research Institute }\end{array}$ \\
\hline $\begin{array}{r}\text { Is the invited manuscript } \\
\text { for consideration in a } \\
\text { Special Issue? : }\end{array}$ & Not applicable (regular submission) \\
\hline
\end{tabular}




\section{Discussion of "Clogging of pervious concrete pile caused by soil piping: an approximate experimental study" ${ }^{1}$}

\section{By Yousif A. H. Dallo ${ }^{2}$ and Guizhong $\mathrm{Xu}^{3}$}

Cui et al. (2017) [here and after referred as "the paper under discussion"] have presented a very good paper dealing with clogging of previous concrete piles. Mixtures of gravel and sand were used to investigate the clogging. In the paper under discussion, it is assumed that the "skeleton" is composed of coarse gravel with particle sizes ranging from 4.75 to $9.5 \mathrm{~mm}$ and the "movable particles" are the sand particle sizes ranging from 0.3 to $4.75 \mathrm{~mm}$. Actually, such an assumption is applicable mostly for gap-graded soils, but not applicable for widely graded sand-gravel such as the mixture (M1-S-14) tested in the paper under discussion, see Fig. 1. For this mixture, the skeleton particles are not ranging from 4.75 to $9.5 \mathrm{~mm}$ as assumed in the paper under discussion, but they are ranging from about 1.2 to $9.5 \mathrm{~mm}$, as proven here both computationally and by reanalyzing some of the experimental data presented in the paper under discussion.

\footnotetext{
${ }^{1}$ Canadian Geotechnical Journal, https://doi.org/10.1139/cgj-2017-0238

${ }^{2}$ Associate professor, Ph.D. Geotechnical Research Institute, Civil engineering department, Yancheng Institute of Technology, No.9, Xiwang Road, Yancheng, Jiangsu 224051, P. R. China. E-mail: dalloyousif@gmail.com.

${ }^{3}$ Associate professor, Ph.D. Geotechnical Research Institute, Yancheng Institute of Technology, No.9, Xiwang Road, Yancheng, Jiangsu 224051, P. R. China.
} 
The particle size that distinguishes the skeleton particles from the movable particles is called the delimiting particle size, DPS, and it can be obtained either experimentally, Binner et al. (2010), or computationally from Aberg (1992) as:

$$
D P S=\frac{2 c}{2 c+1+2 d} \frac{A_{a}}{B_{a}^{2}}
$$

$A_{a}$ and $B_{a}$ can be computed as

$$
A_{a}=\int_{y_{a}}^{1} \frac{y}{x_{(y)}} d y-y_{a} \int_{y_{a}}^{1} \frac{d y}{x_{(y)}}
$$

and

$$
B_{a}=\int_{y_{a}}^{1} \frac{d y}{x_{(y)}}
$$

where $y_{a}$ is the finer percentage corresponding to the delimiting particle size DPS. $y$ is the percentage passing corresponding to a particle diameter $x_{(y)}$. The coefficient $c$ is a factor accounts for the shape of the soil particles, $c=0.75$ for sand and gravel; and $d$ is a constant depends on the relative density of the soil. Eqs.(1 to 3 ) can be solved by a trial and error process for the value of DPS and $y_{a}$, for more details see Aberg (1992). By solving Eqs.(1 to 3 ) the discusser found that the delimiting particle size is about 1.4 $\mathrm{mm}$. This value coincides very well with the value of the maximum size of erodible particle [i.e. moveable particles] that obtained from reanalyzing the experimental data presented in Table 7 [in the paper under discussion]. The discusser used the method of Kenney and Lau (1985) to determine the maximum size of moveable particles, MSMP, 
by extending the grain size distribution of the mixture M1-S-14 before the test to match the grain size distribution of the first and the second layers after the test, see Fig. 2. According to the method of Kenney and Lau (1985) the point of divergence between the grain size distribution curves is considered as the MSMP. As can be seen from Fig. 2 the MSMP is $1.2 \mathrm{~mm}$ which is very close to the value obtained from the computational method of Aberg (1992).

Fig. 1 Grain size distribution of the sand-gravel mixtures.

Fig. 2 The method of Kenney and Lau (1985) to determine the maximum size of movable particle

\section{Acknowledgments}

This study is supported by Six Talented Peaks Project in Jiangsu Province, China (Grant No.2015-JNHB-018)

\section{References}

Aberg, B. (1992). "Void ratio of noncohesive soils and similar materials" J. Geotech. Eng., 118(9), 1315-1333. 
Binner R., Homberg U., Prohaska S., Kalbe U., \& Witt K. J. (2010) Identification of Descriptive Parameters of the Soil Pore Structure using Experiments and CT Data. Proccedings of the Fifth International Conference on Scour and Erosion, American Society of Civil Engineers, 397-407.

Cui, X., Zhang, J., Chen, D., Li, S., Jin, Q., Zheng, and Y., Cui, S. (2017) “Clogging of pervious concrete pile caused by soil piping: an approximate experimental study", Can. Geotech. J., 2018, 55(7): 999-1015, https://doi.org/10.1139/cgj-2017-0238.

Kenney, T.C. and Lau, D. (1985) "Internal stability of granular filters". Can. Geotech. J., 22(2), 215-225. 


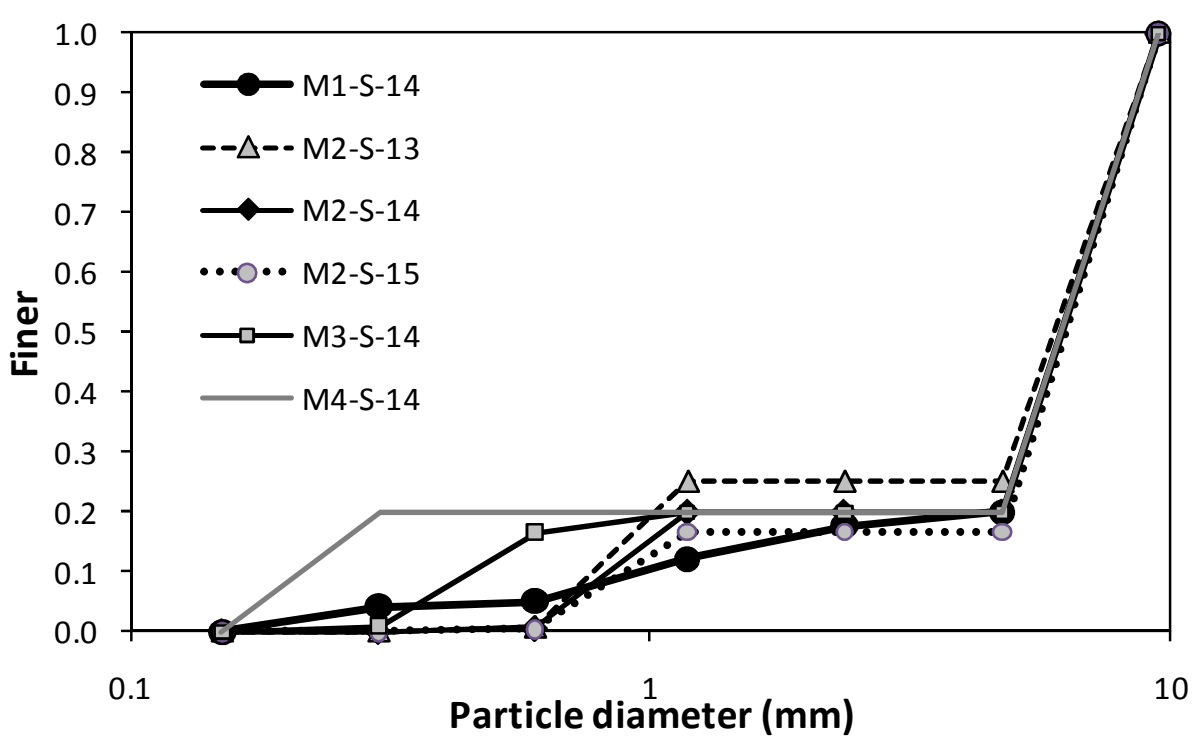

Fig. 1 Grain size distribution of the sand-gravel mixtures. 


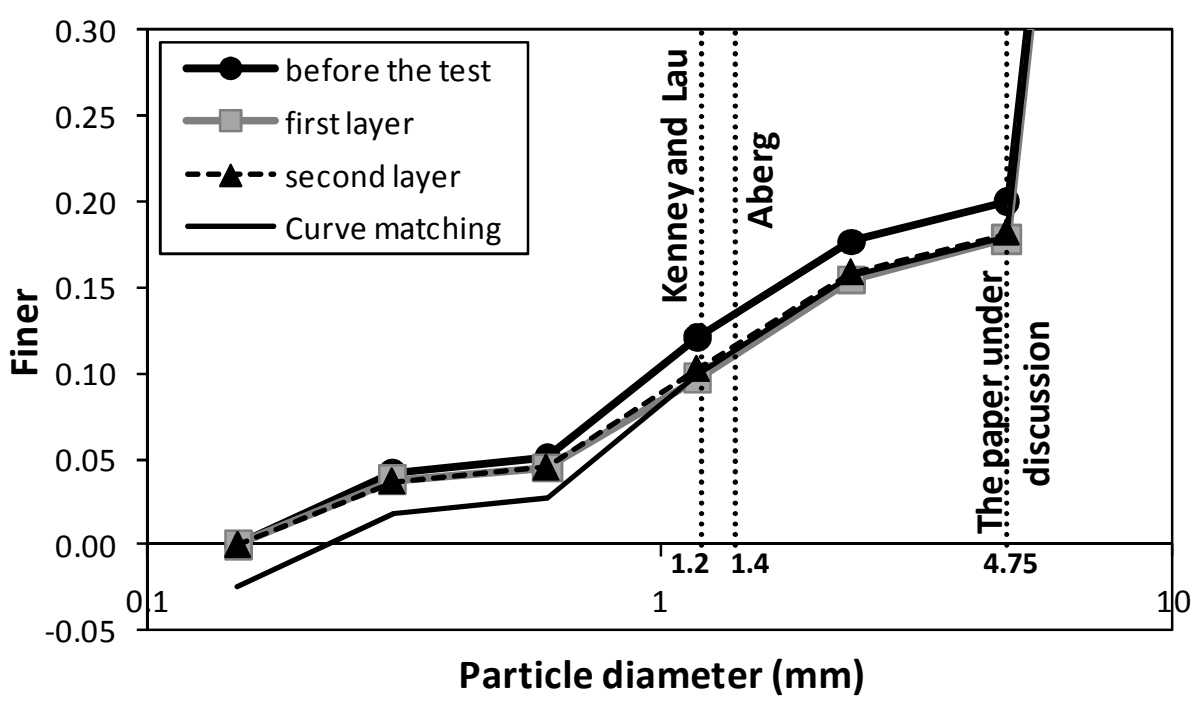

Fig. 2 The method of Kenney and Lau (1985) to determine the maximum size of movable particle 